\title{
The prognostic value and therapeutic target role of stathmin-1 in urinary bladder cancer
}

\author{
T Hemdan $^{1,5}$, M Lindén ${ }^{1,5}$, S B Lind ${ }^{2,3}$, A V Namuduri ${ }^{1}$, E Sjöstedt ${ }^{2}$, T D de Ståhl ${ }^{4}$, A Asplund ${ }^{2}$, P-U Malmström ${ }^{1}$ \\ and U Segersten ${ }^{\star}, 1$ \\ ${ }^{1}$ Department of Surgical Sciences, Uppsala University, Uppsala 751 85, Sweden; ${ }^{2}$ Department of Immunology, Genetics and \\ Pathology, Uppsala University, Uppsala 751 85, Sweden; ${ }^{3}$ Department of Chemistry-BMC, Science for Life Laboratory, Uppsala \\ University, Uppsala 751 24, Sweden and ${ }^{4}$ Department of Oncology-Pathology, Karolinska Institute, Stockholm 171 76, Sweden
}

Background: The oncoprotein-18/stathmin 1 (STMN1), involved in cell progression and migration, is associated with clinical outcome in breast cancer. Here we aim to investigate its clinical significance in urinary bladder cancer and its possibilities as a therapeutic target.

Methods: Immunohistochemical analyses of STMN1 protein expression were performed in three patient cohorts: cohort I ( $n=115$ Ta, $n=115$ T1, $n=112$ T2-4 stages), cohort II, based on randomised controlled trials ( $n=239$ T1-T4), and cohort III of primary tumour/matched metastasis $(n=90$ T1-T4). The effects of STMN1 on cell proliferation and migration were evaluated in the urinary bladder cancer cell line, T24, by inhibiting STMN1-cellular expression using siRNA.

Results: In cohort I, high STMN1 expression correlated to shorter disease-specific survival hazard ratio $(\mathrm{HR})=2.04(95 \%$ confidence interval $(\mathrm{Cl}) 1.13-3.68 ; P=0.02)$, elevated $p 53-(P<0.001)$ and Ki67-protein levels $(P<0.001)$. The survival result was validated in cohort II: $\mathrm{HR}=1.76(95 \% \mathrm{Cl} 1.04-2.99 ; P=0.03)$. In the metastatic bladder cancer material, $70 \%$ of the patients were STMN1positive in both the primary tumour and matched metastases. In vitro, the growth and migration of the T24 cells were significantly reduced $(P<0.01, P<0.0001$, respectively), when transfecting the cells with STMN1-siRNA.

Conclusions: STMN1 protein expression has prognostic significance but is primarily a potential treatment target in urinary bladder cancer.

Urinary bladder cancer is the fifth most common cancer type in Europe with 116000 new cases and 37000 deaths annually (Boyle and Ferlay, 2005). To improve the management of patients and to decrease the mortality rate, identification of prognostic, predictive markers and therapeutic targets is of great importance. A major effort, in the bladder cancer field, has been performed to find gene signatures correlating to, for example, progression, carcinoma in situ and metastatic potential (Mitra et al, 2009). However, the results still need to be validated in larger tumour materials to reach the clinic. In addition, to individualise patient management, several therapeutic options must be available, requiring novel therapeutic targets expressed in advanced dedifferentiated and metastatic bladder cancer, causing bladder cancer death.

The microtubule-destabilising protein, stathmin 1/oncoprotein18 (STMN1), has an important role during mitosis, influencing cell cycle progression (Rana et al, 2008; Belletti and Baldassarre, 2011). In addition, STMN1 is involved in tumour metastasis, cell invasion and migration (Baldassarre et al, 2005; Hsieh et al, 2010; Jeon et al, 2010; Zheng et al, 2010; Lei et al, 2011; Tan et al, 2012; Byrne et al, 2013; Chen et al, 2013) and is a considered therapeutic cancer target (Belletti and Baldassarre, 2011). Mutated p53 and levels of STMN1 are closely related in cancer and thereby STMN1 is suggested as a p53-target gene (Yuan et al, 2006; Singer et al, 2007; Oren and Rotter, 2010). Interestingly, in ovarian cancer it has been demonstrated that STMN1, itself, affects the stability and transcriptional activity of mutated p53 (Sonego et al, 2013). STMN1 is also suggested as a prognostic marker in many different cancer forms, for example, brain, breast, colorectal, endometrial, nasopharyngeal and liver cancer (Yuan et al, 2006; Ngo et al, 2007; Saal et al, 2007; Golouh et al, 2008; Zheng et al, 2010; Tan et al,

*Correspondence: Dr U Segersten; E-mail: ulrika.segersten@surgsci.uu.se

${ }^{5}$ These authors contributed equally to this work.

Revised 12 June 2014; accepted 3 July 2014; published online 29 July 2014

(C) 2014 Cancer Research UK. All rights reserved 0007-0920/14 
2012; Hsu et al, 2013; Wik et al, 2013). Although high levels of STMN1 are associated with taxol resistance in several cancer types (Iancu et al, 2000; Mistry and Atweh, 2006; Alli et al, 2007; Singer et al, 2007; Rana et al, 2008; Han et al, 2013; Miceli et al, 2013), in ovarian clear cell adenocarcinoma and in bladder cancer other microtubule-related proteins, and not STMN1, are demonstrated to be the main predictors of taxol response (Aoki et al, 2009; Wosnitzer et al, 2011). As described above, STMN1 is studied in various numbers of cancers but is not as well characterised in bladder cancer. To our knowledge, the urinary bladder cancer cohorts previously studied, including the above mentioned study (Wosnitzer et al, 2011), have consisted of non-muscle invasive tumours (Dubosq et al, 2011) or basal and luminal subtypes of muscle-invasive bladder cancer (Choi et al, 2014). In the latter study, the basal phenotype, enriched with the rare squamous differentiation, had a poorer prognosis and higher STMN1 gene expression among many other p53-related genes.

Thereby, in this study the objectives were to examine the prognostic relevance of the STMN1 protein in both non-muscleand muscle-invasive diseases, of the common histology-type transitional cell carcinoma, as well as to determine its possible role as a therapeutic target in advanced metastatic bladder cancer.

\section{MATERIALS AND METHODS}

Patient material and follow-up. Informed consent was obtained from the patients included in the cohorts described below.

Cohort I. The Uppsala University Hospital patients included in cohort I were diagnosed with bladder cancer between 1984 and 2005. Use of these patient samples for protein profiling was approved by the regional ethical review board of Uppsala (reference number 2005:339). The tumour material compromises a wide-range tissue microarray (TMA) of prospectively collected primary tumours $(n=115 \mathrm{Ta}, n=115 \mathrm{~T} 1$ and $n=112 \mathrm{~T} 2-\mathrm{T} 4)$. Clinicohistopathological data are presented in Supplementary Table 1.

At follow-up of the prospective material, the non-muscleinvasive patients were categorised as having none, few or frequent recurrences. The group 'few recurrences' was defined as less than three recurrent tumours within 18 months, whereas the group 'frequent recurrences' was defined as three or more recurrences within the same time period. Progression was defined as shift of the tumour into a higher stage. Months to progression within 5 years were on average 23.3 months (s.d., 14.4 range 2.0-55.0 months). Follow-up times for non-recurrent and non-progressing cases were $\geqslant 4$ and $\geqslant 5$ years, respectively. In addition to progression-free survival (PFS), the follow-up also included overall survival (OS) and disease-specific survival (DSS). The end points of OS, PFS and DSS were calculated from the date of surgery to the date of event or last follow-up. Cohort I has been published previously (Fristrup et al, 2012; Lindén et al, 2013; Boman et al, 2013a, b).

Validation cohort II. Patients in cohort II were 239 Swedish T1-T4 patients included in two randomised controlled trials (Sherif et al, 2004). Clinical and histopathological data of the cohort are presented in Supplementary Table 2. Primary end points were OS, DSS and cisplatin response. OS and DSS were calculated from the date of study inclusion to event or last follow-up date. Cisplatinresponse was defined as downstaging to no or non-invasive tumour in the cystectomy specimen. Ethical permit to use these samples for protein expression evaluation was obtained from regional ethical review board of Uppsala (reference number 2008:136).

Cohort III. Cohort III represents a retrospective primary tumour/ matched metastases whole-section material from 90 patients treated at Uppsala University Hospital between 1976 and 2003. The 90 patients were divided into two main groups: seventy primary tumours having one corresponding metastasis and 20 primary tumours matched with multiple metastases (two or three metastases). Ten of the 46 regional lymph glands were sentinel nodes from eight patients (two patients with two sentinel lymph glands each). Primary tumour tissues from 24 of the 90 patients are present in cohort I and use of this material has the same ethical review board number as for cohort I (see above). Histopathological and clinical data are presented in Supplementary Table 3. This cohort has been studied previously (Gardmark et al, 2005).

Normal tissue. In addition, normal/non-malignant urothelium tissue specimens from sixth bladder cancer patients and one patient with benign bladder condition were also analysed for STMN1 protein expression.

Tissue microarray construction. As previously described (Boman et al, 2013b), the tissue from the cohorts (described above) were retrospectively collected for the production of the TMA (cohorts I and II). Representative tissue areas were identified by pathologist, classifying the tumours according to the WHO grading system of 2004 (Sauter et al, 2004). In addition, the TMA was constructed using an automated instrument, ATA-27 (Beecher Instruments, Sun Prairie, WI, USA). All tissue samples were represented in duplicate tissue cores $(1 \mathrm{~mm})$.

Immunohistochemistry. Automated immunohistochemistry (IHC) was performed as published (Segersten et al, 2009) using an Autostainer 480 instrument (Lab Vision, Fremont, CA, USA). Briefly, the tissue slides were incubated for $30 \mathrm{~min}$ with the primary mouse monoclonal STMN1 antibody (sc-48362, Santa Cruz Biotechnology, Santa Cruz, CA, USA) diluted 1/250 before using a dextran polymer visualisation system (UltraVision LP HRP polymer, Lab Vision) for detection of the protein expression. Negative controls were produced by using PBS instead of primary antibody.

Evaluating the STMN1 expression, a previously published scoring system of IHC was used (Segersten et al, 2009). Intensity was scored as weak (score 1), medium (score 2) or high (score 3 ). The extent of staining was scored as the number of cells stained: $<25 \%$ (score 1), 25-75\% (score 2), $>75 \%$ (score 3 ). The final score was calculated as the product of the intensity and extentscores. Score category 0: negative (score 0); score category 1: weak expression (score 1-3); score category 2: moderate/strong expression (score 4-9).

Moreover, IHC analyses of the p53- and Ki67-protein levels were performed according to the protocol described above, with the primary mouse monoclonal p53-DO7 (DAKO, Glostrup, Denmark) and Ki67-MIB1 (Dako) diluted $1 / 500$ and $1 / 600$, respectively. Scoring and cutoff value of $>20 \%$ cells stained as positive, for both p53 and Ki67, were according to previous publications (Saint et al, 2004; Margulis et al, 2006).

The scoring was performed, for each protein, by two independent observers.

Cell culture and transfection. A human muscle-invasive urinary bladder cell line, T24, obtained from the American Type Culture Collection (ATCC, Manassas, VA, USA) was cultured in RPMI1640 (Life Technologies, Carlsbad, CA, USA) with 5\% FBS (Life Technologies) and $1 \%$ penicillin/streptomycin (Life Technologies). The cells were transfected in six-well plates with a $5^{\prime}$ siRNA (AM16708, Life Technologies) and a $3^{\prime}$ siRNA, (s8093, Life Technologies), directed against the STMN1 mRNA using Lipofectamine (Life Technologies) as a transfecting agent according to the manufacturer's protocol. Two controls were used, one with only the transfection agent lipofectamine and one adding scrambled siRNA (4390843, Life Technologies) without a specific 
mRNA target. The $3^{\prime}$ siRNA was used in the following proliferation assay.

Proliferation assay. Transfected T24 cells (as described above) were seeded in 96-well plates and incubated for $24 \mathrm{~h}$ allowing the cells to attach and grow. MTS (3-(4,5-dimethylthiazol-2-yl)-5(3-carboxymethoxyphenyl)-2-(4-sulfophenyl)-2H-tetrazolium) assay from Promega (Fitchburg, WI, USA) was used to measure cell viability after $24,32,48,56,84,104$ and 128 h of seeding.

Invasion assay. The effect of STMN1 on the invasive ability of T24 cells was evaluated using a 96-well extracellular matrix (ECM) chamber assay (Cellbiolabs Inc, San Diego, CA, USA). Briefly, the lower chambers were filled with RPMI-1640-medium (Life Technologies), using 10\% FBS as an attractant component. T24 cells transfected with STMN1 $3^{\prime}$ siRNA and scrambled siRNA as described above were seeded in the upper chambers in serum-free medium. After incubation for $20 \mathrm{~h}$ at $37^{\circ} \mathrm{C}$, the cells migrating through the ECM membrane were lysed and quantified using CyQuant GR Dye (Cellbiolabs Inc). The fluorescence was read at $480 \mathrm{~nm} / 520 \mathrm{~nm}$.

Western blot. The Western blot analysis was performed according to previously published protocol (Lindén et al, 2012) with the differences that the total cell protein lysates were of T24 cell line origin and the following antibodies were used: (i) primary antibodies; the monoclonal mouse anti-STMN1 antibody (sc-48362, Santa Cruz Biotechnology) used for IHC (see above) and the polyclonal rabbit anti- $\beta$-actin antibody (RB-9421, Waltham, MA, USA), (ii) secondary antibodies; sheep anti-mouse (NA931V, GE Healthcare, Little Chalfont, UK) for STMN1 and goat anti-rabbit (sc-2004, Santa Cruz Biotechnology) for $\beta$-actin.

Statistical analysis. Statistical analyses were performed using the SPSS 20.0 (IBM SPSS Statistics, Armonk, NY, USA) software. Correlation analyses of protein expression with the clinical variables age, gender, stage, grade and recurrence were assessed using the Spearman's or the Pearson's $\chi^{2}$ (two-sided tests) when appropriate. For recurrence, the statistical analyses were performed in three groups (none, few or frequent recurrences) and in two groups (recurrence: yes or no). Survival analyses for OS, DSS and PFS were performed using log-rank test and survival curves were estimated by the Kaplan-Meier method. Univariate and multivariate Cox's proportional hazards regression analyses were performed, adjusting for age, gender, T-stage and grade. In the statistical analysis, comparisons between following score categories were performed: (0 vs 1 vs 2$),(0 v s 1,2)$ or $(0,1$ vs 2$)$. A $P$-value $<0.05$ was considered significant.

The in vitro experiments were evaluated using Student's $t$-test (two-sided) and the analyses are based on at least three independent experiments. For cell proliferation and invasion assays, number of replicas in each experiment were six at least 20 wells, for treated and untreated cells, to determine significant difference $(P$-value $<0.05)$.

\section{RESULTS}

A clear, distinct cytoplasmic STMN1 staining was observed in the urinary bladder cancer tissue, both non-muscle- and muscleinvasive tumours, as well as in bladder cancer metastases (Figure 1). The majority (five out of seven) of the investigated non-malignant bladder tissue specimens were STMN1-negative (Figure 1A) and the rest (two out of seven) were classified as having category 1 intensity. The pattern of the IHC stainings was in concordance with a previous bladder cancer publication of STMN1 stainings (Wosnitzer et al, 2011) and with the human protein atlas validation of the antibody in normal and bladder cancer tissue. The following interobserver $\kappa$ values were obtained

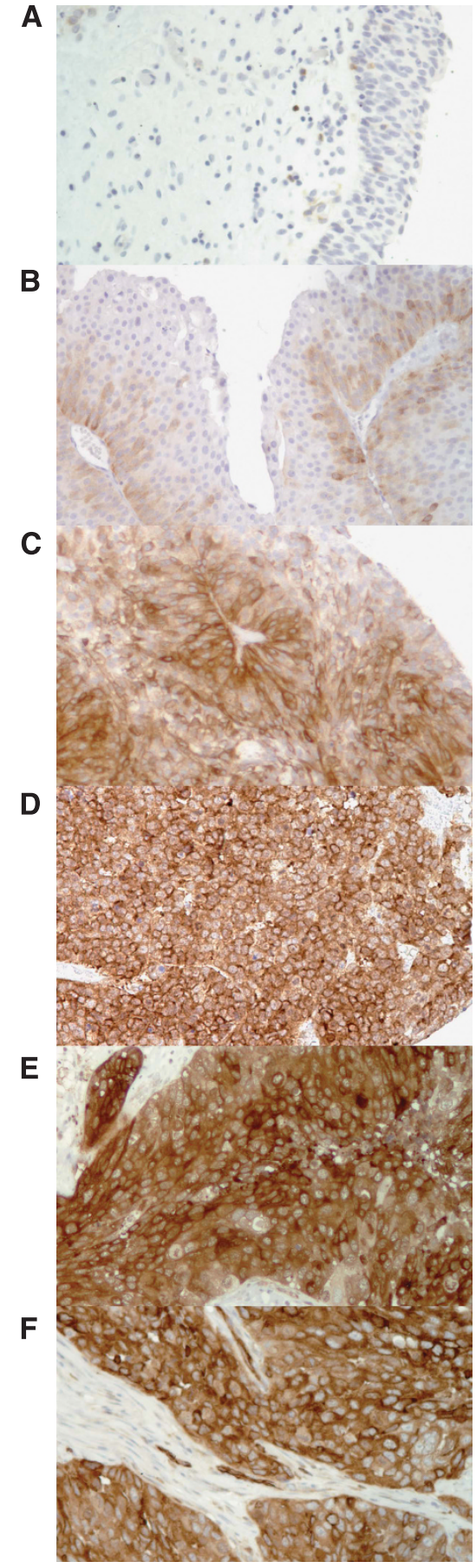

Figure 1. Cytoplasmic STMN1 expression in different urinary bladder cancer tumour stages. (A) Normal $(\times 20)$ with negative expression, (B) low-grade Ta tumour $(\times 20)$ with weak expression, (C) high-grade T1 tumour $(\times 20)$ with moderate/strong expression and (D) high-grade T2 tumour $(\times 20)$ with moderate/strong expression. Moderate/strong expression of STMN1 in metastatic urinary bladder cancer exemplified in $\mathbf{E}$. A high-grade T3 primary tumour $(\times 20)$ and $(\mathbf{F})$ matching sentinel lymph node metastasis $(\times 20)$.

for manual IHC scoring of: STMN1: 0.73 (cohort I), 0.71 (cohort II), 0.76 (cohort III); p53: 0.70 (cohort I); Ki67: 0.75 (cohort I).

\section{Correlation of STMN1 expression to clinical data}

Cohort I. In the statistical analysis examining the correlation between STMN1 expression, score categories: (0 vs 1 vs 2), (0 vs 1, 2) 
or (0, 1 vs 2$)$, and basic and survival variables, following results were significant.

Statistical calculations of the cytoplasmic STMN1 expression, in the 342 TMA tumours, revealed that STMN1 strong staining (tumours belonging to score category 2 ) significantly correlated to higher stage $(P<0.01)$, high grade $(P<0.001)$ and shorter OS and DSS (Figure 2). Adjusting for stage, age and gender using multivariate Cox's proportional hazards regression analyses resulted in following hazard ratios (HRs), confidence interval (CI) and $P$-values: in T1-4 patients: DSS $(0,1$ vs 2 : $\mathrm{HR}=1.83,95 \%$ CI 1.09-3.08; $P=0.02)$; in subgroup T2-T4 patients: OS (0 vs 2: $\mathrm{HR}=1.77,95 \%$ CI $1.02-3.07 ; P=0.04)$ and DSS $(0,1$ vs 2 : $\mathrm{HR}=2.04,95 \% \mathrm{CI} 1.13-3.68 ; P=0.02$ ). In addition, in muscleinvasive bladder cancer, log-rank analysis of DSS (STMN1 score: 0 vs 2) demonstrated to be of borderline significant $(P=0.053$, data not shown). However, when correcting for stage, age and gender there was significantly shorter DSS for patients with tumours staining strongly for STMN1 $(\mathrm{HR}=2.1,95 \%$ CI 1.04-4.25; $P=0.04$ ) compared with those with negative tumours. There was no correlation between STMN1 expression and age, gender, recurrence or PFS.

Validation cohort II. In cohort II, we were able to validate that high tumour expression of STMN1 is correlated to higher risk of

A

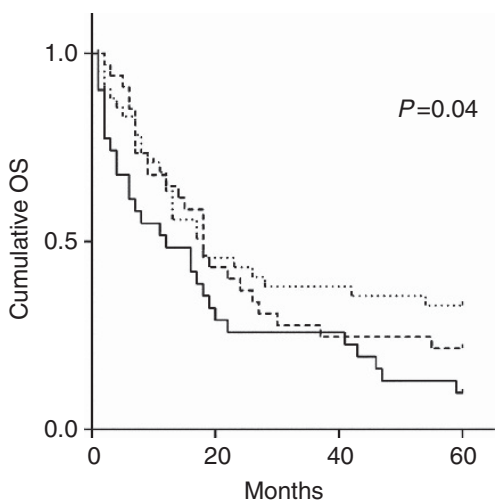

death in cancer within 2 years in T2-T4 patients (Figure 2D, Table 1). We were not able to validate in cohort II that shorter 5 -year OS was associated to overexpression of STMN1, as seen in cohort I (Figure 2A). STMN1 expression was not related to age, gender, stage (T1-2 vs T3-4) or cisplatin response. As cohort II only consists of three $\mathrm{T} 1$ tumours and the rest $\mathrm{T} 2-\mathrm{T} 4$ tumours (Supplementary Table 2), we could not perform survival analysis on T1-T4 group or Spearman's or the Pearson's $\chi^{2}$ analysis on all tumour stages, grade, recurrence or PFS.

STMN1 expression in primary tumours and matched metastases. Representative images of the immunoreactivities of metastatic tissues are supplied in Figure $1 \mathrm{E}$ and $\mathrm{F}$ and the STMN1 expression in the patient material containing primary tumour and metastases is presented in Supplementary Table 3. In the total tumour material, $83 \%$ (75 out of 90 ) of the primary tumours and $79 \%$ (92 out of 116) of the metastases were STMN1-positive (score category 1 or 2 ). The expression of STMN1 in matched metastases was stronger in 19\% (17 out of 90 ), weaker in $27 \%$ (24 out of 90 ), the same in $44 \%$ (40 out of 90 ) or heterogenous expression among several metastases/patient in $10 \%$ ( 9 out of 90 ), compared with primary tumour. In addition, for $70 \%$ (63 out of 90) of the patients, STMN1 was expressed both in primary and matched metastases.

B

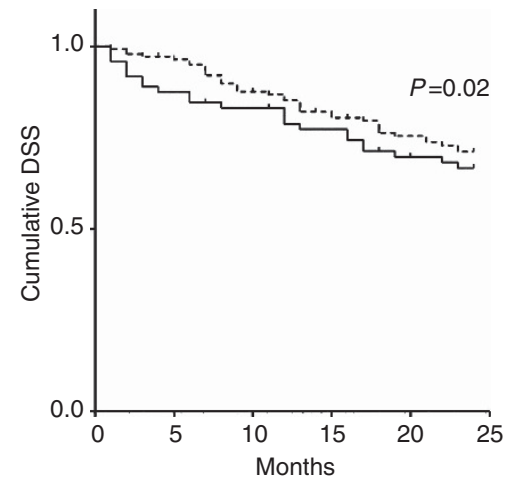

No. remaining

cases

Neg./weak exp. $151 \quad 110 \quad 81$

Mod./strong exp. $76 \quad 55 \quad 41$

Mod/strong exp. 33

C

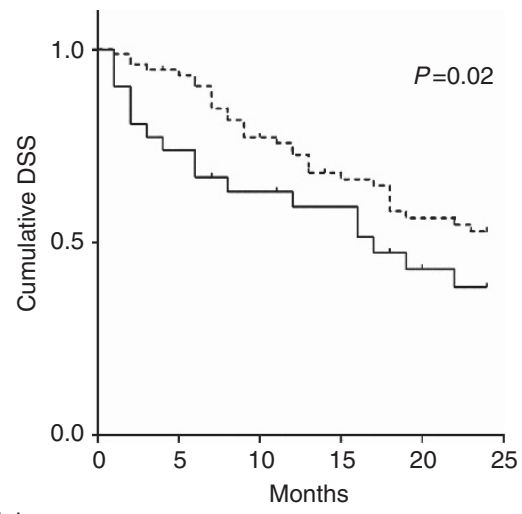

No. remaining

cases

Neg./weak exp. 79

Mod./strong exp. 33
49

15
D

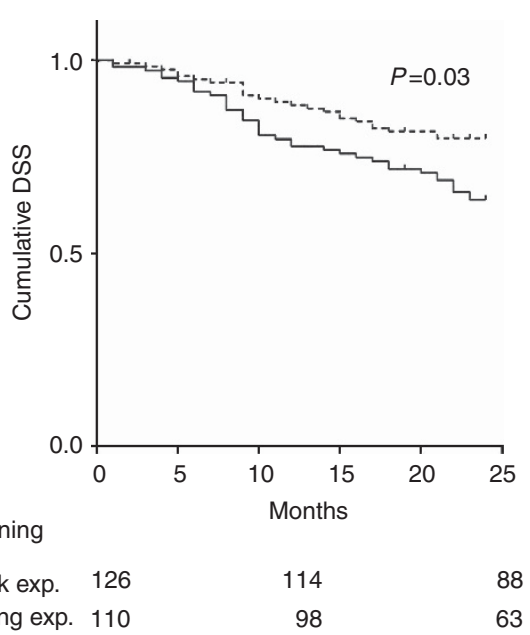

Figure 2. Kaplan-Meier plots describing the correlation of STMN1 to survival. In advanced bladder cancer patients (cohort I), STMN1 overexpression was correlated to shorter (A) OS in T2-T4 patients and to shorter (B) DSS in T1-T4 patients. In cohort I (C) as well as in cohort II (D) T2-T4 patients with moderate/strong STMN1-expressing tumours had a higher risk of cancer-specific death within 2 years. Log-rank test results are displayed for each Kaplan-Meier plot. The $P$-values are the adjusted values from the multivariate analyses, correcting for stage, age and gender. (Negative exp. = dotted line, neg./weak or weak exp. = dashed line and mod./strong exp. = solid line.) 
In the subgroup with only one matched metastasis (70 patients), $81 \%(n=57)$ of the primary tumours and $74 \%(n=52)$ of the metastases stained positive for STMN1 (Figure 3A). For the majority of the patients $69 \%(n=48)$, both primary tumour and matched metastasis expressed STMN1 (score category 1 or 2). The highest score category 2 was observed for $40 \%(n=28)$ of the primary tumours and $39 \%(n=27)$ of the metastases (Figure $3 \mathrm{~A}$ ). In addition, $50 \%(n=35)$ of the metastases were in the same score category as its primary tumour (Figure 3C). Interestingly, $20 \%$ $(n=14)$ of the metastases showed a higher expression than matched primary tumours (Figure 3C). Notably, 4 of these 14 patients had an entirely negative primary tumour.

In the subgroup of patients with multiple metastases, 95\% (19 out of 20) presented at least one metastasis positive for STMN1 (Figure 3B). Subgrouping further, we observed that $35 \%(n=7)$ of the patients had all their metastases in the higher score category 2 (Figure 3B) and for three patients all metastases had a higher STMN1 score than corresponding primary tumours (Figure 3C). For the primary tumours, only two were negative and $85 \%(n=17)$ of the patients had a positive primary tumour in combination with at least one positive metastasis. For $75 \%(n=15)$ of the patients all tumours, both primary tumour and all matched metastases, were positive, belonging to either score category 1 or 2 .

In the primary matched metastasis material (90 patients), there were 10 sentinel lymph nodes of 46 regional lymph gland metastases. For all eight patients with sentinel nodes, both primary and matched sentinel nodes were STMN1-positive (score category 1 or 2). Six of the ten sentinel lymph glands had an overexpression of STMN1 (score category 2).

Correlation of STMN1 to p53 and Ki67 protein expression. The protein expression of p53 and the proliferation marker Ki67 were evaluated in bladder cancer tissue represented by cohort I. High STMN1 expression correlated to increased protein expression of p53 $(P<0.001)$ high protein levels of Ki67 $(P<0.001)$.

siRNA knockdown of STMN1 expression. The effort to knockdown the expression of STMN1 in the T24 cell line resulted in a partial knockdown with the $5^{\prime}$ siRNA and a complete knockdown with the $3^{\prime}$ siRNA, as can be seen in Figure 4. When inspecting the

Table 1. Univariate and multivariate Cox regression analyses regarding DSS (2 years) in cohort I and II (T2-T4 patients)

\begin{tabular}{|c|c|c|c|c|c|c|c|c|}
\hline \multirow[b]{3}{*}{ Variable } & \multicolumn{4}{|c|}{ Cohort I (T2-T4, $n=112)$} & \multicolumn{4}{|c|}{ Cohort II (T2-T4, $n=236)$} \\
\hline & \multicolumn{2}{|c|}{ Univariate } & \multicolumn{2}{|c|}{ Multivariate } & \multicolumn{2}{|c|}{ Univariate } & \multicolumn{2}{|c|}{ Multivariate } \\
\hline & HR $(95 \% \mathrm{Cl})$ & $P$-value & HR $(95 \% \mathrm{Cl})$ & $P$-value & HR $(95 \% \mathrm{Cl})$ & $P$-value & $\mathrm{HR}(95 \% \mathrm{Cl})$ & $P$-value \\
\hline \multicolumn{9}{|l|}{ Age } \\
\hline$\leqslant A v$, age $v s>A v$.age & $2.2(1.24-3.88)$ & 0.007 & $2.33(1.30-4.18)$ & 0.004 & $1.69(0.98-2.9)$ & 0.057 & $1.45(0.84-2.52)$ & 0.19 \\
\hline \multicolumn{9}{|l|}{ Gender } \\
\hline Male vs female & $0.81(0.46-1.44)$ & 0.48 & $0.73(0.40-1.31)$ & 0.29 & $1.33(0.72-2.45)$ & 0.36 & $1.11(0.59-2.06)$ & 0.75 \\
\hline \multicolumn{9}{|l|}{ Stage } \\
\hline T2 vs T3, 4 & $1.59(0.84-2.99)$ & 0.15 & $2.0(1.04-3.83)$ & 0.037 & $1.62(0.96-2.74)$ & 0.073 & $1.55(0.91-2.62)$ & 0.11 \\
\hline \multicolumn{9}{|l|}{ STMN1 } \\
\hline 0,1 vs 2 & $1.84(1.04-3.26)$ & 0.037 & $2.04(1.13-3.68)$ & 0.019 & $1.93(1.16-3.22)$ & 0.012 & $1.76(1.04-2.99)$ & 0.030 \\
\hline
\end{tabular}
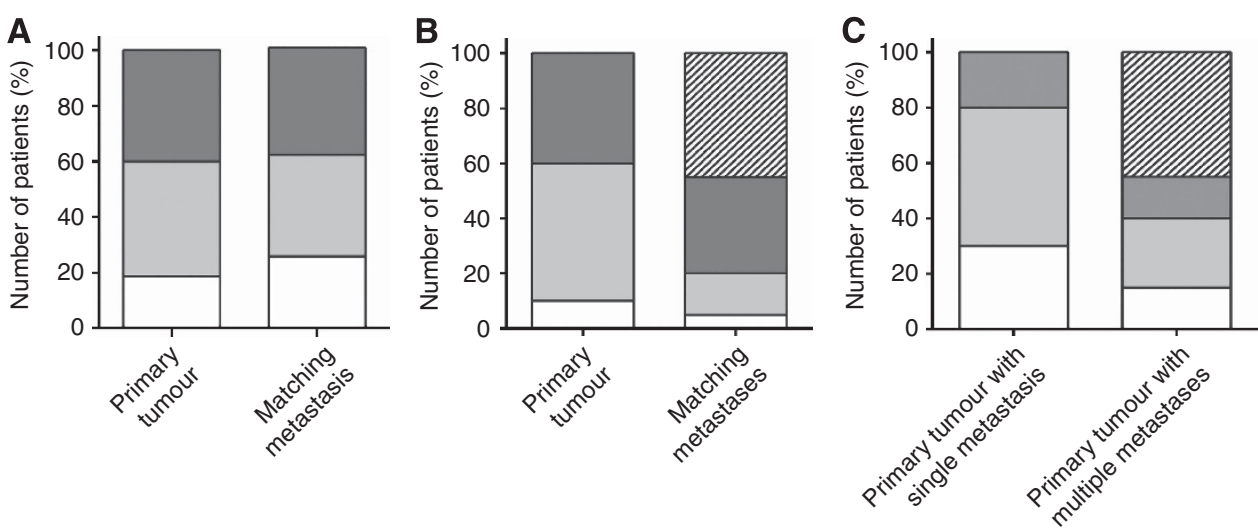

Figure 3. Immunoreactivity score of the STMN1 protein in the metastatic cohort III. (A) Distribution of score categories of primary tumours and metastases from patients with single metastasis. White $=$ score category 0 , light grey $=$ score category 1 and dark grey $=$ score category 2 . (B) Distribution of score categories of primary tumours and metastases from patients with multiple metastases. White $=$ score category 0 , light grey = score category 1 and dark grey=score category 2 and striped $=$ the score categories of the matching metastases are heterogeneous. (C) Summary of primary tumour immunoreactivity in relation to their matching metastases. White =all metastases are in a lower score category than the primary tumour, light grey=all metastases are in the same score category as primary tumour, dark grey=all metastases are in a higher score category than the primary tumour and striped = the score categories of the matching metastases are heterogeneous. 
cell cultures with microscopy, before lysing, there was no morphological difference between treated cells and controls.

Cell proliferation in T24 cells. To evaluate the role of STMN1 in bladder cancer cell proliferation, we performed MTS assays of T24 cells incubated with the STMN1 $3^{\prime}$ siRNA, which had best effect to decrease STMN1 protein levels in the cells. We observed that the STMN1 3 ' siRNA significantly reduced the cell proliferation at 48 $(P=0.0065), 56 \quad(P=0.0005), 84 \quad(P=0.0037), 104 \quad(P=0.0001)$ and $128 \mathrm{~h}(P=0.0011)$ after seeding the siRNA-treated cells (Figure 5).

Invasion assay. To determine the role of STMN1 in bladder cancer cell migration, STMN1 $3^{\prime}$ siRNA-transfected T24 cells were analysed in an ECM chamber assay. The STMN1 $3^{\prime}$ siRNA-treated cells demonstrated a significantly reduced invasion rate $(P<0.0001)$ compared with control cells (Figure 6).

\section{DISCUSSION}

The prognostic value of STMN1 at the protein level has not been fully evaluated in all variants of bladder cancer. The first published study indicating that STMN1 could be of prognostic importance in bladder cancer is the sudy by Saal et al (2007), where STMN1 is proposed, in breast cancer, to be an IHC marker for a phosphatase and tensin homologue/phosphatidylinositol 3-kinase (PTEN/PI3K) pathway activation. In that study, including 80 bladder cancer cases (all stages represented), this PTEN/PI3K-gene signature was

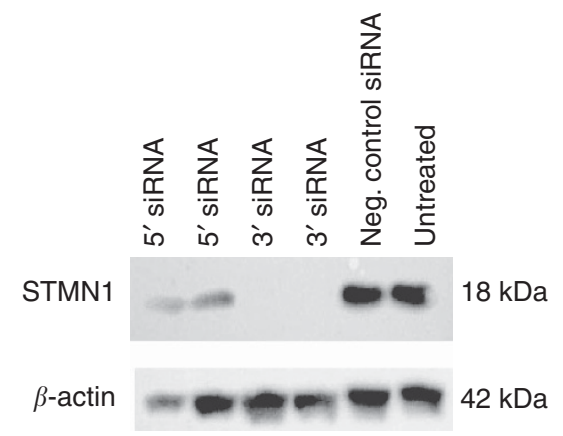

Figure 4. Western blot experiment for evaluation of the effect of siRNAs on STMN1 expression. STMN1 3' siRNA completely inhibited STMN1 protein expression in T24 cells, whereas the $5^{\prime}$ siRNA only reduced the expression. The $\beta$-actin signal was used as loading control.

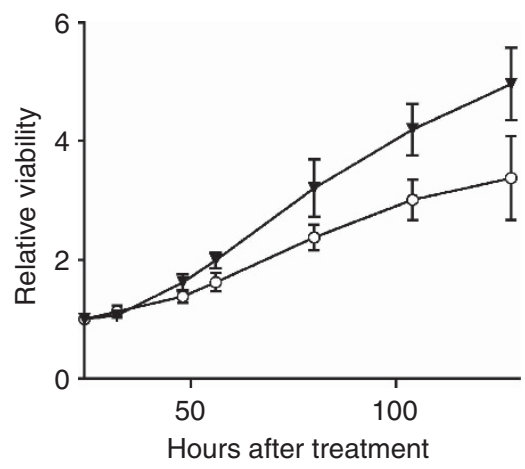

Figure 5. The effect of STMN1 on T24 cell proliferation. The viability of T24 cells transfected with STMN1 siRNA $(O)$ or scrambled siRNA (V) was significantly different $(P<0.01)$ from $48 \mathrm{~h}$ after seeding until the experiment ended after $128 \mathrm{~h}$. Values are the means of three independent experiments with six replicates each, for both treated cells and controls $( \pm \mathrm{SD})$. correlated to poorer prognosis. Our results, at the STMN1 protein level, demonstrating that high STMN1 levels are associated with shorter OS and DSS, in a way, validate the results in the study by Saal et al. Regarding recurrence, Dubosq et al (2011) report that STMN1 is part of a three-gene signature predicting early tumour recurrence. We did not observe any correlation between STMN1 protein expression and tumour recurrence. However, in our cohort we have no data on time to recurrence, which may explain why we cannot validate these results. Regarding prognostic markers, in non-muscle-invasive tumours, markers for recurrence and progression are needed, whereas in muscle-invasive cancer factors identifying risk of metastases and death are in focus. Unfortunately, STMN1 had no correlation to recurrence or progression in non-muscle-invasive patients, even if STMN1 is related to cell invasion, as we demonstrated in the in vitro experiments. Maybe, the invasive ability of the tumour, related to STMN1, is associated to more advanced muscle-invasive tumours, as the T24 cells corresponds to. In muscle-invasive patients, even though we could validate the association between STMN1 and DSS in an independent cohort, the statistical analysis showed that STMN1 is not a strong prognostic factor.

Predictive markers and novel therapeutic targets are of interest in both non-muscle- and muscle-invasive bladder cancer. Concerning therapy prediction, not only taxane but also cisplatinresponse has been suggested to correlate to levels of STMN1 (Singer et al, 2007; Belletti and Baldassarre, 2011). However, we could not validate the association between low STMN1 levels and increased cisplatin sensitivity in muscle-invasive bladder cancer, which is in concordance with the results in a lung cancer study (Jiang et al, 2013).

For a protein to function as a therapeutic target, it has to be expressed in the disease and hopefully in advanced, including metastatic cancer, and this is not often examined before performing functional cell or animal studies. We are fortunate to have access to a unique metastatic bladder cancer cohort, including both the primary tumours and matching metastases and thereby making it possible to determine the expression levels of a therapeutic target protein in relevant tissue. Several observations encourage functional studies of STMN1 as a drug target in bladder cancer cell models; (i) low expression, or even absence, of STMN1 protein in the normal bladder, (ii) high STMN1 expression correlated to higher tumour stage and grade and (iii) expression of

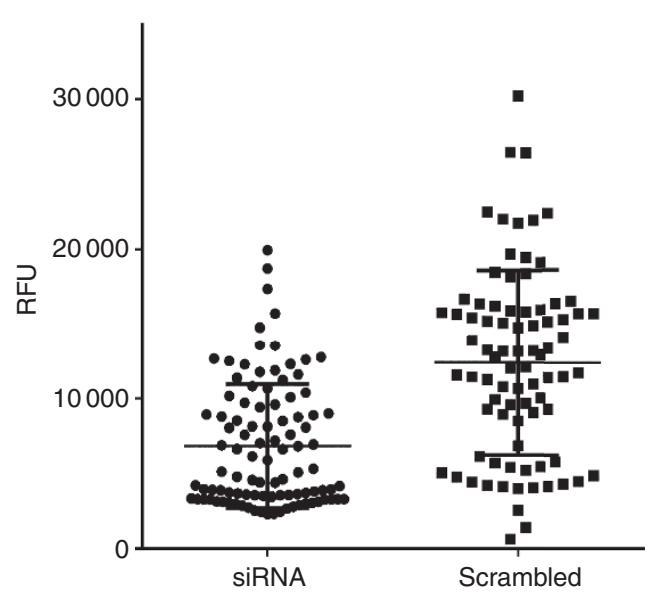

Figure 6. Cell migration ability of T24 cells transfected with STMN1 siRNA scrambled siRNA. Downregulation of STMN1 significantly $(P<0.0001)$ reduced the invasiveness of the T24 cells. Values (Reference Fluorescence Unit $=$ RFU) are the means of four independent experiments with at least 20 replicates each, for both treated cells and controls $( \pm S D)$. Each of the four experiments were significant separately $(P \leqslant 0.01)$. 
STMN1 in the majority (92 out of 116) of investigated metastases. We observed a significant reduction in tumour cell proliferation and cell invasiveness, in vitro, when decreasing the STMN1 protein levels by using siRNA-targeting STMN1. This is in agreement with other in vitro and in vivo studies, where inhibition of STMN1 reduced tumour growth and cell invasion (Baldassarre et al, 2005; Hsieh et al, 2010; Jeon et al, 2010; Zheng et al, 2010; Lei et al, 2011; Phadke et al, 2011; Tan et al, 2012; Byrne et al, 2013; Chen et al, 2013). Our results indicate that STMN1 is of importance for tumour cell proliferation and migration also in bladder cancer. Combining these cell model results with knowledge, that STMN1 is expressed in primary tumours prone to metastasise and also in bladder cancer metastases, strongly suggests that STMN1 is a relevant treatment target in advanced muscle-invasive bladder cancer. In non-muscle-invasive cancer, STMN1 also might function as a therapeutic target, even though in these tumours STMN1 is expressed to a lesser extent and not correlated to progression as mentioned above.

As previously published in hepatocellular cancer (Singer et al, 2007), we also found in bladder cancer a correlation between protein levels of STMN1 and p53 respectively Ki67. We are well aware of the fact that the increase in p53 protein in cancer does not totally correspond to all variants of mutated p53 (Knowles, 2006; Oren and Rotter, 2010). However, it is an indication that there is a relationship between STMN1 and p53 in bladder cancer, as has been reported in other cancers (Yuan et al, 2006; Singer et al, 2007; Oren and Rotter, 2010; Sonego et al, 2013). The significant correlation in bladder cancer tissue between high levels of the proliferation marker Ki67 and increased STMN1-protein expression are in concordance with our in vitro results, where STMN1 is demonstrated to be involved in cell proliferation.

In conclusion, we have been able to show that STMN1 is an important protein for bladder cancer tumour biology and it might be useful for prognostication. However, STMN1 has stronger potential as a therapeutic target. Many novel biomarkers are needed to improve the management and treatment of bladder cancer patients and STMN1 is most likely one of them.

\section{ACKNOWLEDGEMENTS}

We are greatly indebted to the pathologists Christer Busch and Manuel de la Torre for selecting the tumour tissue for the cohorts used in the study. We also thank the members of the Nordic urothelial cancer group contributing to the cancer material in cohort II and the scientists Kenneth Wester, Truls Gårdmark and Amir Sherif for the acquisition of the clinical data for cohort III, including the sentinel node tumours. In addition, the statistician Lisa Wernroth is gratefully acknowledged for skillful assistance. This study was supported by Hillevi Fries Research Fund, Swedish Cancer Society, Lions Fund for Cancer Research, The Foundation in Memory of Johanna Hagstrand and Sigfrid Linnérs, Erik, Karin, Gösta Selanders Foundation, PO Zetterling Foundation and Ake Wiberg Foundation.

\section{CONFLICT OF INTEREST}

The authors declare no conflict of interest.

\section{REFERENCES}

Alli E, Yang JM, Ford JM, Hait WN (2007) Reversal of stathmin-mediated resistance to paclitaxel and vinblastine in human breast carcinoma cells. Mol Pharmacol 71(5): 1233-1240.
Aoki D, Oda Y, Hattori S, Taguchi K, Ohishi Y, Basaki Y, Oie S, Suzuki N, Kono S, Tsuneyoshi M, Ono M, Yanagawa T, Kuwano M (2009) Overexpression of class III beta-tubulin predicts good response to taxane-based chemotherapy in ovarian clear cell adenocarcinoma. Clin Cancer Res 15(4): 1473-1480.

Baldassarre G, Belletti B, Nicoloso MS, Schiappacassi M, Vecchione A, Spessotto P, Morrione A, Canzonieri V, Colombatti A (2005) p27(Kip1)-stathmin interaction influences sarcoma cell migration and invasion. Cancer Cell 7(1): 51-63.

Belletti B, Baldassarre G (2011) Stathmin: a protein with many tasks. New biomarker and potential target in cancer. Expert Opin Ther Targets 15(11): 1249-1266.

Boman K, Larsson AH, Segersten U, Kuteeva E, Johannesson H, Nodin B, Eberhard J, Uhlén M, Malmström PU, Jirström K (2013a) Membranous expression of podocalyxin-like protein is an independent factor of poor prognosis in urothelial bladder cancer. Br J Cancer 108(11): 2321-2328.

Boman K, Segersten U, Ahlgren G, Eberhard J, Uhlén M, Jirström K, Malmström PU (2013b) Decreased expression of RNA-binding motif protein 3 correlates with tumour progression and poor prognosis in urothelial bladder cancer. BMC Urol 13: 17.

Boyle P, Ferlay J (2005) Cancer incidence and mortality in Europe, 2004. Ann Oncol 16(3): 481-488.

Byrne FL, Yang L, Phillips PA, Hansford LM, Fletcher JI, Ormandy CJ, McCarroll JA, Kavallaris M (2013) RNAi-mediated stathmin suppression reduces lung metastasis in an orthotopic neuroblastoma mouse model. Oncogene 33(7): 882-890.

Chen J, Abi-Daoud M, Wang A, Yang X, Zhang X, Feilotter HE, Tron VA (2013) Stathmin 1 is a potential novel oncogene in melanoma. Oncogene 32(10): 1330-1337.

Choi W, Porten S, Kim S, Willis D, Plimack ER, Hoffman-Censits J, Roth B, Cheng T, Tran M, Lee IL, Melquist J, Bondaruk J, Majewski T, Zhang S, Pretzsch S, Baggerly K, Siefker-Radtke A, Czerniak B, Dinney CP, McConkey DJ (2014) Identification of distinct basal and luminal subtypes of muscle-invasive bladder cancer with different sensitivities to frontline chemotherapy. Cancer Cell 25(2): 152-165.

Dubosq F, Ploussard G, Soliman H, Turpin E, Latil A, Desgrandchamps F, de The H, Mongiat-Artus P (2011) Identification of a three-gene expression signature of early recurrence in non-muscle-invasive urothelial cell carcinoma of the bladder. Urol Oncol 30(6): 833-840.

Fristrup N, Ulhøi BP, Birkenkamp-Demtrder K, Mansilla F, Sanchez-Carbayo M, Segersten U, Malmstrm PU, Hartmann A, Palou J, Alvarez-Mgica M, Zieger K, Borre M, Ørntoft TF, Dyrskjøt L (2012) Cathepsin E, Maspin, Plk1, and survivin are promising prognostic protein markers for progression in non-muscle invasive bladder cancer. Am J Pathol 180(5): 1824-1834.

Gardmark T, Wester K, De la Torre M, Carlsson J, Malmstrom PU (2005) Analysis of HER2 expression in primary urinary bladder carcinoma and corresponding metastases. BJU Int 95(7): 982-986.

Golouh R, Cufer T, Sadikov A, Nussdorfer P, Usher PA, Brunner N, Schmitt M, Lesche R, Maier S, Timmermans M, Foekens JA, Martens JW (2008) The prognostic value of Stathmin-1, S100A2, and SYK proteins in ER-positive primary breast cancer patients treated with adjuvant tamoxifen monotherapy: an immunohistochemical study. Breast Cancer Res Treat 110(2): 317-326.

Han ZX, Wang HM, Jiang G, Du XP, Gao XY, Pei DS (2013) Overcoming paclitaxel resistance in lung cancer cells via dual inhibition of stathmin and Bcl-2. Cancer Biother Radiopharm 28(5): 398-405.

Hsieh SY, Huang SF, Yu MC, Yeh TS, Chen TC, Lin YJ, Chang CJ, Sung CM, Lee YL, Hsu CY (2010) Stathmin1 overexpression associated with polyploidy, tumor-cell invasion, early recurrence, and poor prognosis in human hepatoma. Mol Carcinog 49(5): 476-487.

Hsu HP, Li CF, Lee SW, Wu WR, Chen TJ, Chang KY, Liang SS, Tsai CJ, Shiue YL (2013) Overexpression of stathmin 1 confers an independent prognostic indicator in nasopharyngeal carcinoma. Tumour Biol 35(3): 2619-2629.

Iancu C, Mistry SJ, Arkin S, Atweh GF (2000) Taxol and anti-stathmin therapy: a synergistic combination that targets the mitotic spindle. Cancer Res 60(13): 3537-3541.

Jeon TY, Han ME, Lee YW, Lee YS, Kim GH, Song GA, Hur GY, Kim JY, Kim HJ, Yoon S, Baek SY, Kim BS, Kim JB, Oh SO (2010) Overexpression of stathmin 1 in the diffuse type of gastric cancer and its roles in proliferation and migration of gastric cancer cells. Br J Cancer 102(4): $710-718$. 
Jiang H, Yu XM, Zhou XM, Wang XH, Su D (2013) Correlation between microtubule-associated gene expression and chemosensitivity of patients with stage II non-small cell lung cancer. Exp Ther Med 5(5): 1506-1510.

Knowles MA (2006) Molecular subtypes of bladder cancer: Jekyll and Hyde or chalk and cheese? Carcinogenesis 27(3): 361-373.

Lei Y, Huang K, Gao C, Lau QC, Pan H, Xie K, Li J, Liu R, Zhang T, Xie N, Nai HS, Wu H, Dong Q, Zhao X, Nice EC, Huang C, Wei Y (2011) Proteomics identification of ITGB3 as a key regulator in reactive oxygen species-induced migration and invasion of colorectal cancer cells. Mol Cell Proteomics 10(10): M110 005397.

Lindén M, Lind SB, Mayrhofer C, Segersten U, Wester K, Lyutvinskiy Y, Zubarev R, Malmström PU, Pettersson U (2012) Proteomic analysis of urinary biomarker candidates for nonmuscle invasive bladder cancer. Proteomics 12(1): 135-144.

Lindén M, Segersten U, Runeson M, Wester K, Busch C, Pettersson U, Lind SB, Malmstrom PU (2013) Tumour expression of bladder cancer-associated urinary proteins. BJU Int 112(3): 407-415.

Margulis V, Shariat SF, Ashfaq R, Sagalowsky AI, Lotan Y (2006) Ki-67 is an independent predictor of bladder cancer outcome in patients treated with radical cystectomy for organ-confined disease. Clin Cancer Res 12(24): 7369-7373.

Miceli C, Tejada A, Castaneda A, Mistry SJ (2013) Cell cycle inhibition therapy that targets stathmin in in vitro and in vivo models of breast cancer. Cancer Gene Ther 20(5): 298-307.

Mistry SJ, Atweh GF (2006) Therapeutic interactions between stathmin inhibition and chemotherapeutic agents in prostate cancer. Mol Cancer Ther 5(12): 3248-3257.

Mitra AP, Bartsch CC, Cote RJ (2009) Strategies for molecular expression profiling in bladder cancer. Cancer Metastasis Rev 28(3-4): 317-326.

Ngo TT, Peng T, Liang XJ, Akeju O, Pastorino S, Zhang W, Kotliarov Y, Zenklusen JC, Fine HA, Maric D, Wen PY, De Girolami U, Black PM, Wu WW, Shen RF, Jeffries NO, Kang DW, Park JK (2007) The 1 p-encoded protein stathmin and resistance of malignant gliomas to nitrosoureas. J Natl Cancer Inst 99(8): 639-652.

Oren M, Rotter V (2010) Mutant p53 gain-of-function in cancer. Cold Spring Harb Perspect Biol 2(2): a001107.

Phadke AP, Jay CM, Wang Z, Chen S, Liu S, Haddock C, Kumar P, Pappen BO, Rao DD, Templeton NS, Daniels EQ, Webb C, Monsma D, Scott S, Dylewski D, Frieboes HB, Brunicardi FC, Senzer N, Maples PB, Nemunaitis J, Tong AW (2011) In vivo safety and antitumor efficacy of bifunctional small hairpin RNAs specific for the human Stathmin 1 oncoprotein. DNA Cell Biol 30(9): 715-726.

Rana S, Maples PB, Senzer N, Nemunaitis J (2008) Stathmin 1: a novel therapeutic target for anticancer activity. Expert Rev Anticancer Ther 8(9): 1461-1470.

Saal LH, Johansson P, Holm K, Gruvberger-Saal SK, She QB, Maurer M, Koujak S, Ferrando AA, Malmstrom P, Memeo L, Isola J, Bendahl PO, Rosen N, Hibshoosh H, Ringner M, Borg A, Parsons R (2007) Poor prognosis in carcinoma is associated with a gene expression signature of aberrant PTEN tumor suppressor pathway activity. Proc Natl Acad Sci USA 104(18): 7564-7569.

Saint F, Le Frere Belda MA, Quintela R, Hoznek A, Patard JJ, Bellot J, Popov Z, Zafrani ES, Abbou CC, Chopin DK, de Medina SG (2004) Pretreatment p53 nuclear overexpression as a prognostic marker in superficial bladder cancer treated with Bacillus Calmette-Guerin (BCG). Eur Urol 45(4): 475-482.
Sauter G, Algaba F, Amin MB (2004) Noninvasive urothelial neoplasias; WHO classification of noninvasive papillary urothelial tumours. In Elbe JN, Epstein JI, Sesterhenn I (eds A World Health Organization Classification of Tumours. Pathology and Genetics of Tumours of the Urinary System and Male Genital Organs. IARCC: Lyon.

Segersten MU, Edlund EK, Micke P, de la Torre M, Hamberg H, Edvinsson AE, Andersson SE, Malmstrom PU, Wester HK (2009) A novel strategy based on histological protein profiling in-silico for identifying potential biomarkers in urinary bladder cancer. BJU Int 104(11): 1780-1785.

Sherif A, Holmberg L, Rintala E, Mestad O, Nilsson J, Nilsson S, Malmström PU (2004) Neoadjuvant cisplatinum based combination chemotherapy in patients with invasive bladder cancer: a combined analysis of two nordic studies. Eur Urol 45(3): 297-303.

Singer S, Ehemann V, Brauckhoff A, Keith M, Vreden S, Schirmacher P, Breuhahn K (2007) Protumorigenic overexpression of stathmin/Op18 by gain-of-function mutation in $\mathrm{p} 53$ in human hepatocarcinogenesis. Hepatology 46(3): 759-768.

Sonego M, Schiappacassi M, Lovisa S, Dall'Acqua A, Bagnoli M, Lovat F, Libra M, D’Andrea S, Canzonieri V, Militello L, Napoli M, Giorda G, Pivetta B, Mezzanzanica D, Barbareschi M, Valeri B, Canevari S, Colombatti A, Belletti B, Del Sal G, Baldassarre G (2013) Stathmin regulates mutant p53 stability and transcriptional activity in ovarian cancer. EMBO Mol Med 5(5): 707-722.

Tan HT, Wu W, Ng YZ, Zhang X, Yan B, Ong CW, Tan S, Salto-Tellez M, Hooi SC, Chung MC (2012) Proteomic analysis of colorectal cancer metastasis: stathmin-1 revealed as a player in cancer cell migration and prognostic marker. J Proteome Res 11(2): 1433-1445.

Wik E, Birkeland E, Trovik J, Werner HM, Hoivik EA, Mjos S, Krakstad C, Kusonmano K, Mauland K, Stefansson IM, Holst F, Petersen K, Oyan AM, Simon R, Kalland KH, Ricketts W, Akslen LA, Salvesen HB (2013) High phospho-Stathmin(Serine38) expression identifies aggressive endometrial cancer and suggests an association with PI3K inhibition. Clin Cancer Res 19(9): 2331-2341.

Wosnitzer MS, Domingo-Domenech J, Castillo-Martin M, Ritch C, Mansukhani M, Petrylack DP, Benson MC, McKiernan JM, Cordon-Cardo C (2011) Predictive value of microtubule associated proteins tau and stathmin in patients with nonmuscle invasive bladder cancer receiving adjuvant intravesical taxane therapy. J Urol 186(5): 2094-2100.

Yuan RH, Jeng YM, Chen HL, Lai PL, Pan HW, Hsieh FJ, Lin CY, Lee PH, Hsu HC (2006) Stathmin overexpression cooperates with p53 mutation and osteopontin overexpression, and is associated with tumour progression, early recurrence, and poor prognosis in hepatocellular carcinoma. J Pathol 209(4): 549-558.

Zheng P, Liu YX, Chen L, Liu XH, Xiao ZQ, Zhao L, Li GQ, Zhou J, Ding YQ, Li JM (2010) Stathmin, a new target of PRL-3 identified by proteomic methods, plays a key role in progression and metastasis of colorectal cancer. J Proteome Res 9(10): 4897-4905.

This work is published under the standard license to publish agreement. After 12 months the work will become freely available and the license terms will switch to a Creative Commons AttributionNonCommercial-Share Alike 3.0 Unported License.

Supplementary Information accompanies this paper on British Journal of Cancer website (http://www.nature.com/bjc) 